\title{
CrystEngComm
}

Check for updates

Cite this: CrystEngComm, 2021, 23, 6470

Received 21st June 2021,

Accepted 6th August 2021

DOI: 10.1039/d1ce00817j

rsc.li/crystengcomm

\section{How the in situ monitoring of bulk crystalline phases during catalyst activation results in a better understanding of heterogeneous catalysis}

\author{
Simon Penner (1D)
}

\begin{abstract}
The present Highlight article shows the importance of the in situ monitoring of bulk crystalline compounds for a more thorough understanding of heterogeneous catalysts at the intersection of catalysis, materials science, crystallography and inorganic chemistry. Although catalytic action is widely regarded as a purely surface-bound phenomenon, there is increasing evidence that bulk processes can detrimentally or beneficially influence the catalytic properties of various material classes. Such bulk processes include polymorphic transformations, formation of oxygen-deficient structures, transient phases and the formation of a metal-oxide composite. The monitoring of these processes and the subsequent establishment of structure-property relationships are most effective if carried out in situ under real operation conditions. By focusing on synchrotron-based in situ X-ray diffraction as the perfect tool to follow the evolution of crystalline species, we exemplify the strength of the concept with five examples from various areas of catalytic research. As catalyst activation studies are increasingly becoming a hot topic in heterogeneous catalysis, the (self-)activation of oxide- and intermetallic compound-based materials during methanol steam and methane dry reforming is highlighted. The perovskite $\mathrm{LaNiO}_{3}$ is selected as an example to show the complex structural dynamics before and during methane dry reforming, which is only revealed upon monitoring all intermediate crystalline species in the transformation from $\mathrm{LaNiO}_{3}$ into $\mathrm{Ni} / \mathrm{La}_{2} \mathrm{O}_{3} / \mathrm{La}_{2} \mathrm{O}_{2} \mathrm{CO}_{3}$. $\mathrm{ZrO}_{2}$-based materials form the second group, indicating the in situ decomposition of the intermetallic compound $\mathrm{Cu}_{51} \mathrm{Zr}_{14}$ into an epitaxially stabilized $\mathrm{Cu}$ /tetragonal $\mathrm{ZrO}_{2}$ composite during methanol steam reforming, the stability of a $\mathrm{ZrO}_{0.31} \mathrm{C}_{0.69}$ oxycarbide and the gas-phase dependence of the tetragonal-tomonoclinic $\mathrm{ZrO}_{2}$ polymorphic transformation. The latter is the key parameter to the catalytic understanding of $\mathrm{ZrO}_{2}$ and is only appreciated in full detail once it is possible to follow the individual steps of the transformation between the crystalline polymorphic structures. A selected example is devoted to how the monitoring of crystalline reactive carbon during methane dry reforming operation aids in the mechanistic understanding of a $\mathrm{Ni} / \mathrm{MnO}$ catalyst. The most important aspect is the strict use of in situ monitoring of the structural changes occurring during (self-)activation to establish meaningful structure-property relationships allowing conclusions beyond isolated surface chemical aspects.
\end{abstract}

\section{Introduction into the concept}

The central goal in heterogeneous catalytic research is the determination of and knowledge about catalytically active sites. ${ }^{1}$ Characterization of active sites is hampered by the existence of the so-called "pressure" and "materials" gaps. ${ }^{2}$ These are related to the general inability to directly transfer the characterization under ultra-high vacuum conditions to technical conditions at elevated pressures and to derive mechanistic ideas from idealized model systems for usually ill-defined technical powder catalysts. In situ or operando

Institute of Physical Chemistry, University of Innsbruck, Innrain 52c, A-6020 Innsbruck, Austria. E-mail: simon.penner@uibk.ac.at; Tel: +4351250758003 characterization is therefore necessary to eventually monitor the formation and catalytic action of active sites. ${ }^{3}$ The last decades have seen a tremendous rise in the development of such structural and spectroscopic characterization methods, and to date, catalyst characterization under real operating conditions has been possible using a plethora of experimental methods. ${ }^{3}$ These include, but are not limited to, classical catalyst characterization tools like electron microscopy, X-ray photoelectron spectroscopy, infrared spectroscopy and X-ray diffraction. ${ }^{3}$ Although catalysis is an almost exclusively surface-bound phenomenon, bulk in situ characterization tools have contributed greatly to the thorough understanding of catalytic action. Morphological changes of metal particles in reactive gas atmospheres, ${ }^{4}$ gas-phase induced polymorphic transformations of oxides ${ }^{5}$ and reaction-induced exsolution of 
metal particles from perovskites ${ }^{6}$ are all bulk-related phenomena that have a direct catalytic consequence. As the most powerful structural characterization tool, X-ray diffraction is able to deliver qualitative and quantitative information on the structural and crystallographic properties of mostly bulk crystalline species of a catalyst. If it is carried out under in situ reaction conditions, it allows the monitoring of the development of crystalline species as a function of temperature and reaction gas environment and, by correlation with catalytic profiles, also the establishment of structureactivity correlations. ${ }^{7}$ It is worth noting that the in situ monitoring allows the potential influence of transient crystalline species on the catalytic properties to be unraveled, which cannot inherently be studied if ex situ characterization of the spent catalyst state is carried out. This phenomenon is particularly pronounced if the active phase is formed via a pathway of self-activation, e.g., as observed in the decomposition of intermetallic compounds ${ }^{8}$ or the exsolution of metallic particles from perovskite materials. ${ }^{9,10}$

In this Highlight article we provide an introduction to the widescale possibilities of monitoring the in situ development of crystalline (transient) species through pre-treatments and selfactivation to derive a better mechanistic understanding of heterogeneous catalysts and their constituting entities. To generalize the concept, we focus on a set of case studies spanning materials from oxide and oxy-carbides over complex oxides to intermetallic compounds in a number of important reactions, where the monitoring of crystalline species contributes to a thorough understanding. These reactions are methanol steam reforming (MSR) and dry reforming of methane (DRM).

The present Highlight article attempts to raise awareness of the importance of the development and evolution of bulk crystalline species. The impact of especially bulk species on catalysis is very common and widespread, and we show in selected examples how this influence manifests itself in various ways and what we can learn from suitable monitoring of bulk species to derive mechanistic principles and catalyst synthesis strategies. We emphasize here that the impact of the bulk species refers to features that can be directly correlated to activity changes. Of course, these changes have direct consequences for the surface structure of the catalysts that dominate the adsorption and reactivity of reactive species. Naturally, this approach is particularly worthwhile when crystalline species are present and can be studied by the full artillery of in situ bulk structural characterization methods, with in situ X-ray diffraction at the forefront. Hence, the topic of this Highlight article is centered at the intersection of crystal engineering, inorganic chemistry and catalysis. Disentangling the different influences is therefore imperative, and the selected examples will provide evidence of how catalyst synthesis (i.e., inorganic chemistry), crystal engineering/crystallography (i.e., steering the crystal modification of the catalyst material by, e.g., annealing treatments in different gas atmospheres) and catalysis (i.e., the catalytic characterization) always work together to derive general principles.
To show the general validity of the concept, we group the example materials into two classes: $\mathrm{ZrO}_{2}$-based materials ${ }^{5,8}$ and general metal-oxide systems. ${ }^{9-11}$ The latter are studied to highlight the beneficial properties of a crystalline metaloxide phase boundary, either formed by in situ activation or by a co-precipitation approach. The respective samples are (i) a $\mathrm{LaNiO}_{3}$ perovskite that is in situ decomposed into $\mathrm{Ni} / \mathrm{La}_{2} \mathrm{O}_{3} /$ $\mathrm{La}_{2} \mathrm{O}_{2} \mathrm{CO}_{3}$ (ref. 9 and 10) and (ii) a $5 \% \mathrm{Ni} / \mathrm{MnO}$ catalyst. ${ }^{11}$ The recurrent theme is the importance of the in situ monitoring of bulk crystalline phases to establish valid structure-activity correlations. While for $\mathrm{LaNiO}_{3}$ the proper knowledge of the sequence of structural transformations is important, the $5 \%$ $\mathrm{Ni} / \mathrm{MnO}$ catalyst is used to highlight the importance of monitoring the crystalline bulk carbon evolution during DRM to infer pathways of beneficial carbon clean off reactivity. The second materials group is centered around $\mathrm{ZrO}_{2}$, and in three examples, the importance of the proper understanding of the crystalline bulk reactivity is put forward. The three examples comprise the in situ decomposition of a $\mathrm{Cu}_{51} \mathrm{Zr}_{14}$ intermetallic compound during methanol steam reforming, ${ }^{8}$ the in situ oxidation/decomposition of a Zr-oxycarbide material for electrochemical applications ${ }^{12}$ and a general discussion about the complexity of the crystalline $\mathrm{Zr}-\mathrm{O}$ phase diagram, manifesting itself in a complex gas-phase dependence of the tetragonal-to-monoclinic $\mathrm{ZrO}_{2}$ structure transformation. ${ }^{5}$ The latter has tremendous influence on all catalytic applications of $\mathrm{ZrO}_{2}$, and the understanding of the evolution of the bulk crystalline phases is the key to the mechanistic understanding. Despite the obviously different chemical natures of the materials, the examples are carefully selected to emphasize the common links and leading themes that can thus be transformed from one sample to another and allows projections of reactivity along the material axis. For each example discussed in section 2, a short introduction to the state-of-the-art is given to emphasize the existing problems and, in turn, how the proposed monitoring of the evolution of bulk crystalline structures can contribute in finding associated solutions.

\section{Detailing the concept by discussion of selected examples}

\subsection{In situ activation of DRM catalysts: $\mathrm{LaNiO}_{3}$}

To illustrate the importance of monitoring transient crystalline species during catalyst activation, we will focus on the behavior of the archetypical perovskite material $\mathrm{LaNiO}_{3}$ in methane dry reforming. ${ }^{9,10}$ Mostly due to their outstanding redox properties, perovskite materials with the general formula $\mathrm{ABO}_{3}$ have evolved as a particularly promising catalyst class for methane dry reforming. ${ }^{13}$ To form active phases, perovskites are used as precursor materials and are converted into active metal/oxide materials by dedicated activation treatments, either in a hydrogen atmosphere or directly in the $\mathrm{CO}_{2} / \mathrm{CH}_{4}$ dry reforming mixture. $\mathrm{LaNiO}_{3}$ is a highly active DRM pre-catalyst that can be transformed into a $\mathrm{Ni} / \mathrm{La}_{2} \mathrm{O}_{3} / \mathrm{La}_{2} \mathrm{O}_{2} \mathrm{CO}_{3}$ composite by the activation treatment. ${ }^{9,10} \mathrm{Ex}$ situ characterization of the spent 
catalyst state in fact reveals the final structure of $\mathrm{LaNiO}_{3}$ after activation, but gives no answer on the individual steps of $\mathrm{LaNiO}_{3}$ activation and eventual differences between hydrogen or DRM self-activation. Establishment of structure-activity correlations is therefore basically excluded. Fueled by a number of studies hinting towards the importance of in situ monitoring of structural catalyst activation, ${ }^{14,15}$ we have embarked on a detailed in situ study of $\mathrm{LaNiO}_{3}$ during catalyst activation by synchrotron-based X-ray diffraction. ${ }^{16,17}$ Due to the high beam intensity and the fast detector read-out, we were able to deliver unprecedented insight into the structural transformations during activation and the direct relation to catalytic DRM activity. In fact, the structural transformation of $\mathrm{LaNiO}_{3}$ into $\mathrm{Ni} / \mathrm{La}_{2} \mathrm{O}_{3} / \mathrm{La}_{2} \mathrm{O}_{2} \mathrm{CO}_{3}$ is very complex and involves a number of consecutive steps that all feature a distinct catalytic fingerprint (Fig. 1). The first transformation is a polymorphic transformation of orthorhombic $\mathrm{LaNiO}_{3}$ into a tetragonal structure, followed by the formation of oxygen-deficient $\mathrm{LaNiO}_{2.7}$ and $\mathrm{LaNiO}_{2.5}$. Both appear as crystalline phases (Fig. 1A) and are already associated with moderate DRM activity (Fig. 1B and C). The crucial step for strong acceleration of DRM activity is the decomposition of those sub-stoichiometric structures into the crystalline Ruddlesden-Popper structure $\mathrm{La}_{2} \mathrm{NiO}_{4}$ and the in-parallel exsolution of metallic $\mathrm{Ni}$ and formation of $\mathrm{La}_{2} \mathrm{O}_{3}$, which quickly carbonates to monoclinic $\mathrm{La}_{2} \mathrm{O}_{2} \mathrm{CO}_{3}$ (Fig. $1 \mathrm{~B}$ and C). $\mathrm{La}_{2} \mathrm{NiO}_{4}$ itself is a transient crystalline structure, which decomposes at $620{ }^{\circ} \mathrm{C}$ into metallic $\mathrm{Ni}$ and $\mathrm{La}_{2} \mathrm{O}_{3} /$ monoclinic $\mathrm{La}_{2} \mathrm{O}_{2} \mathrm{CO}_{3}$, giving rise to strong acceleration of activity. Above $680{ }^{\circ} \mathrm{C}$, a polymorphic monoclinic-hexagonal $\mathrm{La}_{2} \mathrm{O}_{2} \mathrm{CO}_{3}$ transformation sets in, which is accompanied by exceeding the stability limit of the La-oxycarbonate structures beyond $770{ }^{\circ} \mathrm{C}$, where hexagonal $\mathrm{La}_{2} \mathrm{O}_{3}$ is re-formed by $\mathrm{CO}_{2}$ release. The final structure, persisting upon re-cooling to room temperature, is $\mathrm{Ni} / \mathrm{La}_{2} \mathrm{O}_{3} / \mathrm{La}_{2} \mathrm{O}_{2} \mathrm{CO}_{3}$. The latter is re-formed during the cooling process. Hence, between $500{ }^{\circ} \mathrm{C}$ and $800{ }^{\circ} \mathrm{C}$ the catalytic activity can be directly related to a set of transformations of crystalline species (Fig. 1B and C). We might even explain the dip in catalytic activity between $620{ }^{\circ} \mathrm{C}$ and $650{ }^{\circ} \mathrm{C}$ by the evolution of crystalline species: in this temperature region, $\mathrm{La}_{2} \mathrm{NiO}_{4}$ starts to fully decompose, releasing lattice oxygen to oxidize the exsolved metallic $\mathrm{Ni}$ on the surface. $\mathrm{NiO}$ is a poor methane activator; hence the catalytic activity decreases as long as the oxygen supply does not cease. Only above $650{ }^{\circ} \mathrm{C}$, the decomposition of $\mathrm{La}_{2} \mathrm{NiO}_{4}$ is complete and no oxygen can be delivered anymore. The Ni particles, hence, remain metallic, and the DRM activity increases due to improved methane activation. By comparing the self-activation properties under DRM operation conditions to those during pre-reduction in a hydrogen atmosphere we were able to show the crucial role of the crystalline $\mathrm{La}_{2} \mathrm{NiO}_{4}$ compound, which is absent during hydrogen reduction. Direct transformation of the sub-stoichiometric structures into $\mathrm{Ni} / \mathrm{La}_{2} \mathrm{O}_{3}$ was observed. ${ }^{9}$

Already this example highlights the importance of strictly following the in situ evolution of crystalline structures for a full appreciation of structure-activity correlations. This refers
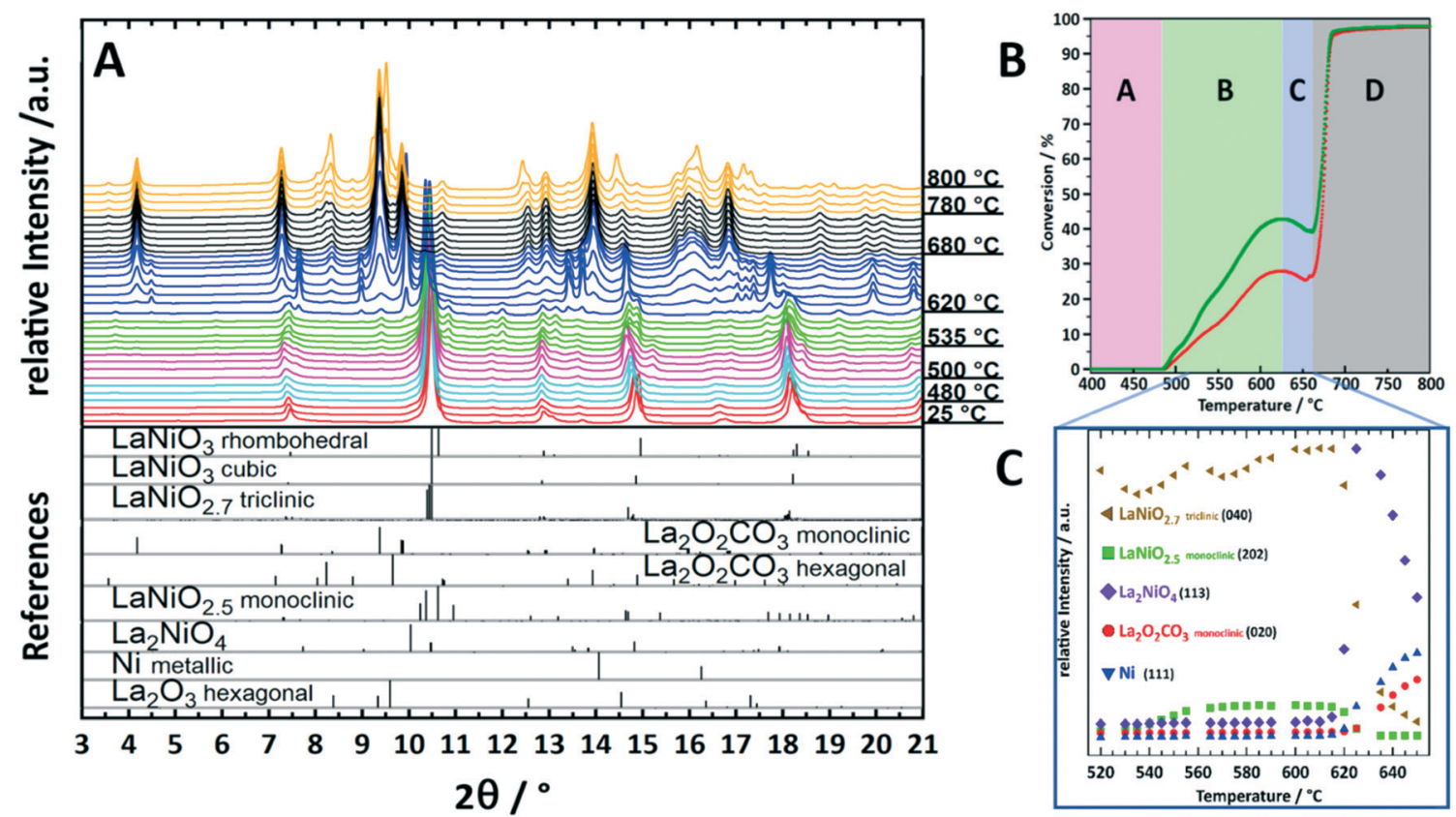

Fig. 1 Characterization and structure-activity correlation during decomposition of crystalline $\mathrm{LaNiO}_{3}$ in a $1: 1 \mathrm{CO}_{2}: \mathrm{CH}_{4}$ dry reforming mixture up to $800{ }^{\circ} \mathrm{C}$. Panel A: Synchrotron-based in situ X-ray diffractograms during DRM operation. The diffractograms with similar structures are colored accordingly. The reference patterns are shown as bars at the bottom of the panel. Panel B: Catalytic DRM profile of LaNiO $\mathrm{N}_{3}$. The sections from A-D indicate temperature regions, where important structural alterations are present. ${ }^{9}$ Panel C: Semi-quantitative analysis by the Le Bail method of the peak intensities of important structures in the temperature region $520-660{ }^{\circ} \mathrm{C}$ as discussed in ref. 9 . To facilitate the correlation between the DRM activity and structural evolution in panel $\mathrm{C}$, the temperature region is marked in panel $\mathrm{B}$ on the temperature axis. Reproduced with permission from ref. 9. Copyright American Chemical Society, 2021. 
to the formation of intermediate structures, but also to the crystalline monoclinic $\mathrm{La}_{2} \mathrm{O}_{2} \mathrm{CO}_{3}$ structure, which is most crucial for the necessary reversible $\mathrm{CO}_{2}$ activation/release cycle. Thanks to the crystalline nature of the participating structures, the bifunctionally operating $\mathrm{Ni} / \mathrm{La}_{2} \mathrm{O}_{2} \mathrm{CO}_{3}$ interface, providing both methane activation (metallic $\mathrm{Ni}$ ) and $\mathrm{CO}_{2}$ activation (carbonation of $\mathrm{La}_{2} \mathrm{O}_{3}$ to monoclinic $\mathrm{La}_{2}$ $\mathrm{O}_{2} \mathrm{CO}_{3}$ ), can be directly visualized and studied. Even more, we were able to show the exclusiveness of the presence of the monoclinic $\mathrm{La}_{2} \mathrm{O}_{2} \mathrm{CO}_{3}$ structure with respect to enhanced DRM activity.

\subsection{In situ activation of methanol steam reforming catalysts: $\mathrm{Cu}_{51} \mathrm{Zr}_{14}$}

Intermetallic compounds have recently evolved as a promising materials class with a wide range of application possibilities in catalytic research. ${ }^{18-21}$ Although stable intermetallic compounds are used directly as catalyst materials, they are increasingly used as catalyst precursor structures, where the active species is formed through an activation step. The concept itself is very much related to the perovskite activation $^{9,10}$ in a sense that the well-defined intermetallic compound starting structure paves the way to structurally steer the decomposition towards a metal-oxide composite with superior catalytic properties. ${ }^{8}$ We have shown the capabilities of this approach for a number of intermetallic compounds in a variety of reactions, ${ }^{22}$ but exemplify it for $\mathrm{Cu}_{51} \mathrm{Zr}_{14}$ in the methanol steam reforming reaction. ${ }^{8}$ Cu-containing compounds, with a technically used $\mathrm{Cu} / \mathrm{ZnO} / \mathrm{Al}_{2} \mathrm{O}_{3}$ system and $\mathrm{ZrO}_{2}$-doped composites as particular promising stable catalysts, represent the state-ofthe-art. ${ }^{23,24}$ Materials development for $\mathrm{Cu}$ compounds in methanol steam reforming is essentially directed towards improving the poor sintering stability of $\mathrm{Cu}$ particles at elevated temperatures. ${ }^{24}$ Zr-based $\mathrm{Cu}$ intermetallic compounds represent a material class, where this drawback is circumvented by in situ activation and stabilization of the $\mathrm{Cu}$ particles using an extended $\mathrm{ZrO}_{2}$ matrix in situ formed by activation. ${ }^{8,25,26} \mathrm{Cu}_{51} \mathrm{Zr}_{14}$ stands out particularly in terms of yielding a highly active MSR composite material after in situ decomposition. As shown in Fig. 2A, the crystalline $\mathrm{Cu}_{51} \mathrm{Z}_{14}$ structure is in situ decomposed during methanol steam reforming exclusively into a crystalline $\mathrm{Cu}$ /tetragonal $\mathrm{ZrO}_{2}$ composite. This is insofar remarkable as $\mathrm{Cu}$ is known to stabilize the tetragonal $\mathrm{ZrO}_{2}$ structure, which in contact to $\mathrm{Cu}$ yields a particularly $\mathrm{CO}_{2}$-selective methanol steam reforming catalyst, ${ }^{27}$ even activating itself during four consecutive methanol steam reforming cycles (Fig. 2B). The particular importance of a well-defined crystalline starting $\mathrm{Cu}_{51} \mathrm{Zr}_{14}$ compound is reflected in the close match of the cubic $\mathrm{Cu}$ and the tetragonal $\mathrm{ZrO}_{2}$ lattice constants, providing energy gain by epitaxial stabilization of the $\mathrm{Cu}$ /tetragonal $\mathrm{ZrO}_{2}$ interface. ${ }^{25}$ As for the perovskite case study discussed in section 2.1., the bifunctional operating mechanism for methanol steam reforming through methanol activation on metallic $\mathrm{Cu}$ and water activation on $\mathrm{ZrO}_{2}$ and/or at special crystalline interfacial sites is evident. ${ }^{8}$ Although the
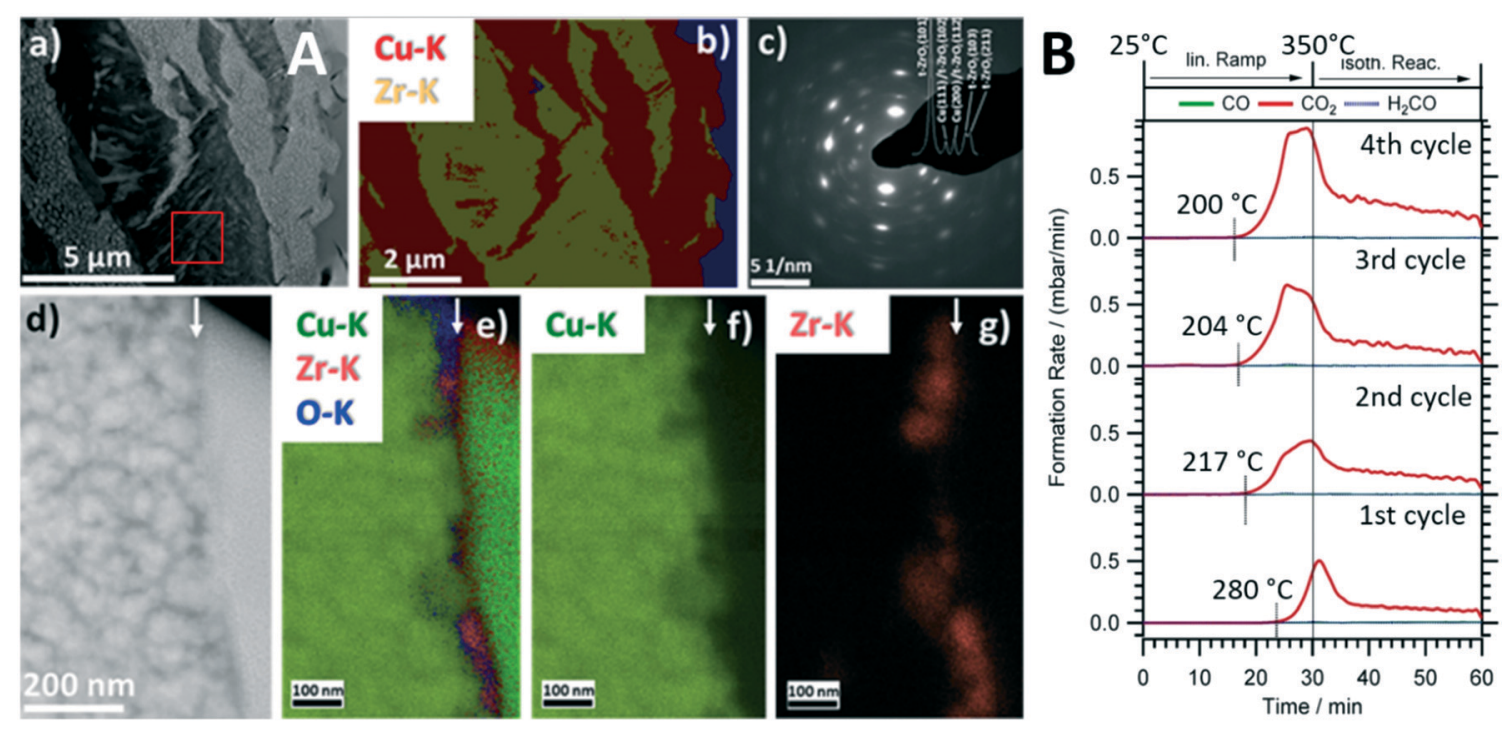

Fig. 2 Structural and catalytic characterization of the in situ decomposition of crystalline $\mathrm{Cu}_{51} \mathrm{Zr}_{14}$ during methanol steam reforming operation. Panel A: Electron microscopy analysis of the decomposed state after the first catalytic cycle. Subpanel a): Overview high-angle annular dark-field (HAADF) image. Subpanel b): EDX analysis based on the $\mathrm{Cu}-\mathrm{K}$ and $\mathrm{Zr}-\mathrm{K}$ intensities of the same region. Subpanel c): Selected area electron diffraction (SAED) pattern of the region shown in subpanel a) marked by a red square. Subpanel d): $\mathrm{HAADF}$ image of the $\mathrm{Cu}$-tetragonal $\mathrm{ZrO}_{2}$ interface (the surface is marked by a white arrow). Subpanels e)-g): EDX analysis of the same region. The superimposed $\mathrm{Cu}-\mathrm{K}, \mathrm{Zr}-\mathrm{K}$ and $\mathrm{O}-\mathrm{K}$ intensities are shown in e); the individual maps of the $\mathrm{Cu}-\mathrm{K}$ and $\mathrm{Zr}-\mathrm{K}$ intensities are shown in $\mathrm{f}$ ) and g). The green intensity on the right part of subpanel e) refers to Pt used in the FIB cutting process. Panel B: Four consecutive catalytic methanol steam reforming profiles using crystalline $\mathrm{Cu}_{51} \mathrm{Zr}_{14}$. Reaction conditions detailed in ref. 8. Reproduced with permission from ref. 8, Wiley-VCH, 2021. 
decomposition of such intermetallic compounds especially during methanol steam reforming has been known for some time, ${ }^{8,22}$ it is exactly the crystalline nature of the $\mathrm{Cu}_{51} \mathrm{Zr}_{14}$ compound that allows the transition of the precursor structure into the active phase by, e.g., in situ X-ray diffraction correlated to catalytic selectivity and activity to be monitored.

\subsection{Stability of oxycarbides: $\mathrm{ZrO}_{0.31} \mathrm{C}_{0.69}$}

Interstitial alloys of transition metals, mostly known as metal carbides and nitrides, have been extensively studied because of their promising physico-chemical properties differing from the parent metals. ${ }^{28-30}$ Interstitial incorporation of carbon into the lattice of group 4-6 transition metals modifies both their structural $^{29,31}$ and electronic properties. Their associated chemical activity ${ }^{29,30,33}$ is similar to or sometimes even exceeds that of Pt-group metals. ${ }^{32}$ Transition metal carbides (TMCs) are therefore suitable catalysts for reforming processes, e.g., hydrogenation of $\mathrm{CO}$ and the water gas shift (WGS) reaction. ${ }^{34}$ Important for electrochemical applications, the electrochemical stability of such transition metal carbides over wide potential and $\mathrm{pH}$ ranges is important for their use as low cost electrocatalysts in electrochemical reactions. ${ }^{35,36}$ The recurrent structural theme of most of those materials is the intrinsic propensity to be unstable towards oxycarbide or even oxide formation due to their high affinity to oxygen. ${ }^{37-39}$ In fact, it has been shown for many examples, including the most wellstudied $\mathrm{TiO}_{x} \mathrm{C}_{y}$ and $\mathrm{MoO}_{x} \mathrm{C}_{y}$ materials, ${ }^{37-40}$ that the active phase of such transition metal carbides is an oxy-carbide structure and that the respective carbide under reaction conditions is an idealized benchmark state. ${ }^{40}$ Having said that, assessing the stability limits under realistic gas and liquid phase (electro-) catalytic conditions is of paramount importance for the use and projection of the performance of similar structures along the material axis. We exemplify this issue on a recently found novel $\mathrm{ZrO}_{0.69} \mathrm{C}_{0.31}$ oxy-carbide material, ${ }^{41}$ which has shown great potential for energy conversion reactions under strongly anodic conditions, e.g., for alcohol or CO oxidation. ${ }^{12}$ To test the stability limits of crystalline $\mathrm{ZrO}_{0.69} \mathrm{C}_{0.31}$ under different gas atmospheres, in situ X-ray diffractograms collected from room temperature to $800{ }^{\circ} \mathrm{C}$ show that the oxycarbide material is stable under reductive conditions in both pure and $\mathrm{Ar}$ diluted $\mathrm{H}_{2}$ (Fig. 3A and B), as well as in $\mathrm{He}$ and $\mathrm{CH}_{4}$ (Fig. 3C and F), with only small amounts of tetragonal $\mathrm{ZrO}_{2}$ formed at high temperatures. In contrast, it is readily oxidized in $\mathrm{O}_{2}$ and $\mathrm{CO}_{2}$ with complete decomposition of $\mathrm{ZrO}_{0.69} \mathrm{C}_{0.31}$ into $\mathrm{ZrO}_{2}$ (Fig. 3D and E). Metallic conductivity of $\mathrm{ZrO}_{0.69} \mathrm{C}_{0.31}$ is preserved if minor amounts of $\mathrm{ZrO}_{2}$ are formed. In the case of complete decomposition, a pronounced increase of the impedance is observed, making the decomposition product an insulating material. The importance of the presence of a crystalline material is reflected in the fact that essentially only tetragonal $\mathrm{ZrO}_{2}$ as a decomposition product, but only in tiny amounts of the ambient-stable monoclinic modification, could be verified by in situ X-ray diffraction. This observation provides the link to the $\mathrm{Cu} / \mathrm{ZrO}_{2}$ case study discussed in section 2.2., as we might infer that for all catalytic applications, either $\mathrm{ZrO}_{0.69} \mathrm{C}_{0.31}$ (if stable), tetragonal $\mathrm{ZrO}_{2}$ alone (in the case of full decomposition) or a $\mathrm{Zr}$ oxy-carbide/tetragonal $\mathrm{ZrO}_{2}$ interface (in the case of partial decomposition) is prevalent. As for $\mathrm{Cu} / \mathrm{ZrO}_{2}$, the crystallinity of $\mathrm{ZrO}_{0.69} \mathrm{C}_{0.31}$ favors inferring the epitaxial stabilization effects between the tetragonal $\mathrm{ZrO}_{0.69} \mathrm{C}_{0.31}$ and tetragonal $\mathrm{ZrO}_{2}$ structures steering the decomposition towards tetragonal $\mathrm{ZrO}_{2}$.

\subsection{Gas phase dependency of the polymorphic $\mathrm{ZrO}_{2}$ structure transformation}

The gas-phase dependence of the crystalline tetragonal-tomonoclinic $\mathrm{ZrO}_{2}$ polymorphic transformation in a nutshell provides the great recurrent theme governing the structural and catalytic properties of the $\mathrm{ZrO}_{2}$-containing materials discussed in the previous sections. It is the central single most important parameter in catalyst development and in the establishment of structure-property relationships, and it very much depends on the crystallinity of the materials which allows the associated structural changes to be monitored. The $\mathrm{Zr}-\mathrm{O}$ phase diagram is complex and involves at least three different crystalline modifications: the ambient-stable monoclinic structure and two tetragonal and cubic metastable high-temperature structures. ${ }^{5}$ The latter two can be stabilized and recovered to room temperature either through external doping, e.g., with $\mathrm{Y}$ (yielding an yttriumstabilized $\mathrm{ZrO}_{2}$ structure used, e.g., as electrolyte and ion conductor in solid oxide fuel cells), via particle size control or via intrinsic "doping" by oxygen vacancies. It is well-known, that tetragonal $\mathrm{ZrO}_{2}$ can be stabilized by oxygen vacancies, and any application of tetragonal $\mathrm{ZrO}_{2}$ relies on the persistence of such vacancies during use to suppress the inevitable structure transformation to monoclinic $\mathrm{ZrO}_{2}{ }^{5}$ As discussed in previous sections, the monoclinic bulk structure appears to be of inferior importance with respect to its use as part of a catalyst material in catalytic experiments, and it is mostly its surface chemistry that dictates its use, e.g., in $\mathrm{Cu}$ / $\mathrm{ZrO}_{2}$ catalysts for methanol steam reforming. ${ }^{24}$ In contrast, tetragonal $\mathrm{ZrO}_{2}$ stands out as bulk crystalline structure and in many of its applications the crystalline bulk properties play an important part in explaining the catalytic reactivity pattern. ${ }^{42}$ The close match of the $\mathrm{Cu}$ and tetragonal $\mathrm{ZrO}_{2}$ lattice constants is one of the most prominent examples, as discussed in sections 2.2. and $2.3 .^{25}$ It is therefore of utter importance to acquire knowledge about the gas-phase dependence of the tetragonal-to-monoclinic $\mathrm{ZrO}_{2}$ structure transformation, although the mechanistic ideas of the transition have been known for several decades. It is the so called martensitic structure transformation, which is athermic and diffusionless and propagates along the cracks of the structure resulting from the action of shear forces. ${ }^{43}$

As indicated in Fig. 4, the influence of the gas atmospheres on the extent of structure transition and therefore the individual weight fractions of still remaining tetragonal $\mathrm{ZrO}_{2}$ and gas-phase induced monoclinic $\mathrm{ZrO}_{2}$ is 

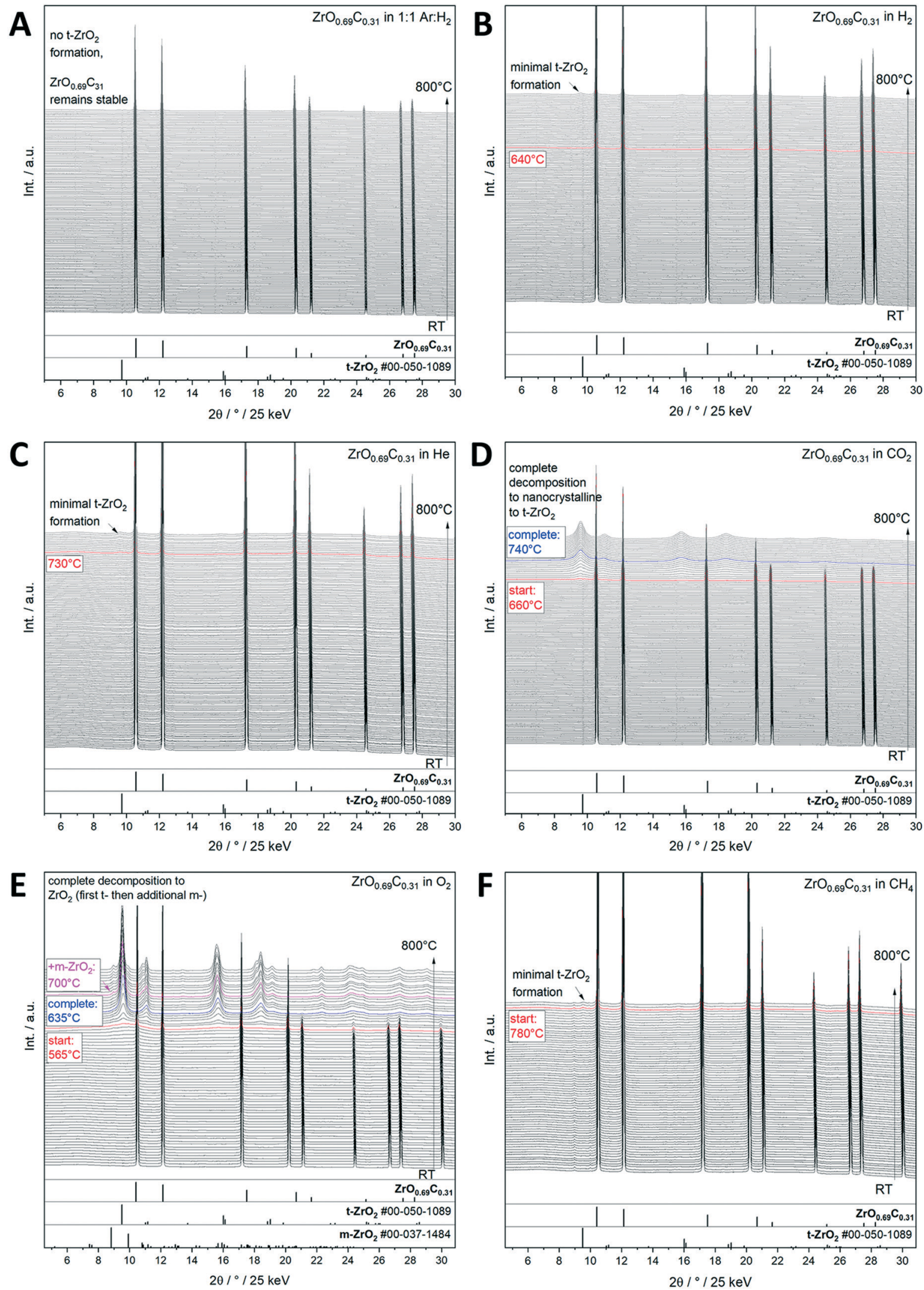

Fig. 3 Decomposition study of crystalline $\mathrm{ZrO}_{0.69} \mathrm{C}_{0.31}$ in selected inert, oxidative and reductive gas atmospheres up to $800{ }^{\circ} \mathrm{C}$ as monitored by synchrotron-based in situ X-ray diffraction. Panel A: $\mathrm{Ar}: \mathrm{H}_{2}$ mixture $=1: 1$, panel B: pure $\mathrm{H}_{2}$, panel C: pure $\mathrm{He}$, panel $\mathrm{D}$ : pure $\mathrm{CO}_{2}$, panel $\mathrm{E}$ : pure $\mathrm{O}_{2}$, and panel $\mathrm{F}$ : pure $\mathrm{CH}_{4}$. The X-ray diffraction patterns are shown as waterfall plots. The temperatures where important structural changes are observed are marked accordingly. Reference patterns are indicated as bars below the diffractograms. In part reproduced with permission from ref. 12 Wiley-VCH, 2021. 

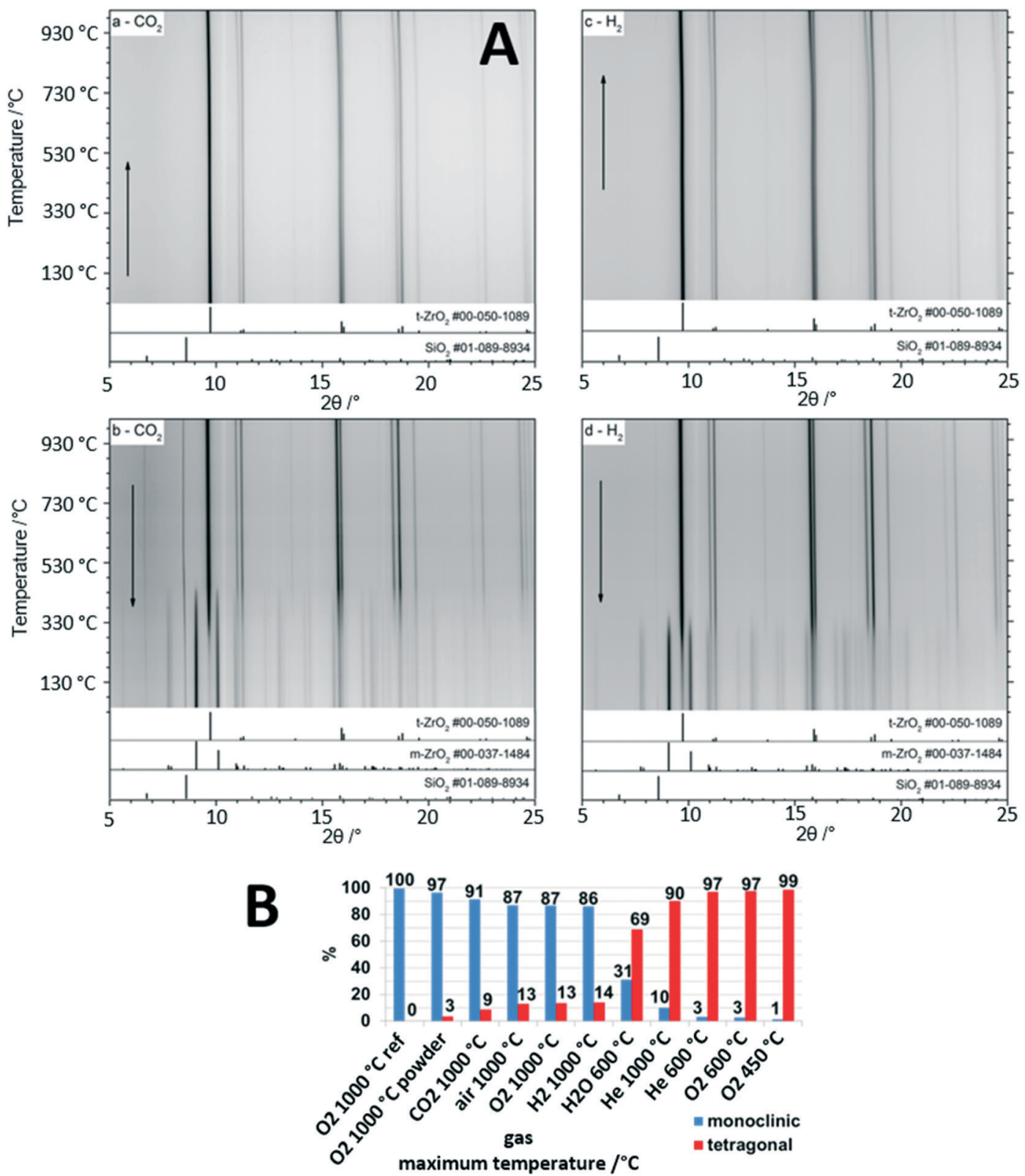

Fig. 4 In situ X-ray diffraction studies of the evolution of crystalline bulk tetragonal $\mathrm{ZrO}_{2}$. Panel A: Temperature-dependence of the tetragonalto-monoclinic $\mathrm{ZrO}_{2}$ structure transformation upon heating and re-cooling in $\mathrm{H}_{2}$ and $\mathrm{CO}_{2}$ from room temperature to $1000{ }^{\circ} \mathrm{C}$ and back. Panel $\mathrm{B}$ : Summary of the weight fraction analysis based on Rietveld refinement of tetragonal and monoclinic $\mathrm{ZrO}_{2}$ after treatments in selected gas atmospheres as indicated. Reproduced in part with permission from ref. 5, Royal Society of Chemistry, 2021.

tremendous. The starting point of each experiment is structure-pure, well crystallized tetragonal $\mathrm{ZrO}_{2}$. In previous studies we have demonstrated the extraordinary stability of tetragonal $\mathrm{ZrO}_{2}$ up to $450{ }^{\circ} \mathrm{C}$, essentially being independent of the treatment conditions. ${ }^{42}$ This also encompasses dry and moist conditions, which is insofar of importance as it allows the use of either structurally stable bulk structure-pure tetragonal $\mathrm{ZrO}_{2}$ or a crystallized metal (mostly $\mathrm{Cu}$ )/tetragonal $\mathrm{ZrO}_{2}$ interface for steam reforming reactions up to typical temperatures of around $400{ }^{\circ} \mathrm{C}$. The astonishing suppression of the transformation to monoclinic $\mathrm{ZrO}_{2}$ is ascribed to the synthesis conditions, which involved water-free precipitation from a $\mathrm{Zr}$ propoxide precursor. ${ }^{42}$ Using this approach, a high number of bulk oxygen defects are retained within the tetragonal $\mathrm{ZrO}_{2}$ structure, which serve as the blockage to the polymorphic transformation and provide extra bulk structural stability. ${ }^{5}$ In due course, as shown in Fig. 4, we tried to deliberately trigger the structure transition by heating tetragonal $\mathrm{ZrO}_{2}$ in selected inert, reductive and oxidative gas environments. Exemplarily highlighted in Fig. 4A, the temperature dependence of the in situ collected X-ray diffractograms are shown under mildly reducing conditions in flowing $\mathrm{CO}_{2}(1 \mathrm{bar})$ and strongly reducing conditions in pure hydrogen $(1 \mathrm{bar})$. The high stability of the crystalline 
tetragonal $\mathrm{ZrO}_{2}$ structure in both atmospheres up to $950{ }^{\circ} \mathrm{C}$ is immediately obvious. The formation of monoclinic $\mathrm{ZrO}_{2}$ is only observed upon re-cooling below around $700{ }^{\circ} \mathrm{C}$ in $\mathrm{CO}_{2}$ and $600{ }^{\circ} \mathrm{C}$ in $\mathrm{H}_{2}$. The onset temperature of the polymorphic transformation is higher (i.e., earlier upon cooling) in $\mathrm{CO}_{2}$, and the amount of monoclinic $\mathrm{ZrO}_{2}$ in the composition mixture upon re-cooling to room temperature is lower in $\mathrm{H}_{2}$. We ascribed the higher transformation temperature in $\mathrm{CO}_{2}$ to a larger crystallite size of tetragonal $\mathrm{ZrO}_{2}$ (making it more unstable towards the structure transformation) and the higher amount of tetragonal $\mathrm{ZrO}_{2}$ in the final phase mixture in $\mathrm{H}_{2}$ to a better stabilization of bulk oxygen vacancies and the suppression of the replenishment of the latter. Fig. 4B summarizes the main features of the gas phase dependence: the amount of persisting tetragonal $\mathrm{ZrO}_{2}$ in the final mixture is higher the more reducing the gas atmosphere is, tetragonal $\mathrm{ZrO}_{2}$ is more stable the lower the temperature is, and moist conditions, even at a comparably low temperature of $873 \mathrm{~K}$, trigger the formation of a considerable amount of monoclinic $\mathrm{ZrO}_{2}$. These findings are of special importance for water-containing reactions, such as methanol steam reforming, as the initially more oxidizing and moist conditions (getting progressively more reducing as the reaction proceeds by forming more hydrogen in the gas outlet) tend to favor the structure transformation. It should be noted that the deduction of these principles is only possible by closely monitoring the bulk structure and reactivity of crystalline tetragonal $\mathrm{ZrO}_{2}$. This is insofar important as in many studies with initially tetragonal $\mathrm{ZrO}_{2}$, once the reaction proceeds at elevated temperatures, a structural mixture of tetragonal and monoclinic $\mathrm{ZrO}_{2}$ is rather present. ${ }^{5,42}$

\subsection{Carbon reactivity}

The deposition of carbon leading to catalyst deactivation is a common phenomenon in various reactions, and much research is put into assessing the carbon reactivity and cleanoff mechanisms. ${ }^{44-47}$ Although carbon deposition is mainly viewed as a nuisance, carbon nevertheless can act as a crucial intermediate in catalytic reactions ${ }^{48}$ and in some cases even contribute beneficially to the overall catalytic properties. ${ }^{11,48}$ By focusing on a selected example in the dry reforming of methane reaction, we show how the monitoring of crystalline carbon species provides insight into the catalytic action of a $\mathrm{Ni} / \mathrm{MnO}$ oxide interface during DRM operation. ${ }^{11}$ The dry reforming of methane reaction is best suited as an illustrative example in this respect, as the reaction of carbon following methane activation is part of the reversible carbon dioxide activation and release cycle. ${ }^{49}$ For La-based Ni catalysts, it is accepted that carbon dioxide activation involves the formation of an La-oxycarbonate that is decomposed through $\mathrm{La}_{2} \mathrm{O}_{2} \mathrm{CO}_{3}(\mathrm{~s})+\mathrm{C}(\mathrm{s}) \rightarrow \mathrm{La}_{2} \mathrm{O}_{3}(\mathrm{~s})+2 \mathrm{CO}(\mathrm{g}) \cdot{ }^{9}$ The reactivity of the carbon intermediate is therefore crucial in the syngas production. Crystalline surface carbon can be formed via the Boudouard equilibrium, via direct decomposition of methane or via the reverse coal gasification process and, as such, is strongly individually dependent on the reaction conditions and structural and/or chemical properties of the catalyst material (e.g., particle sizes and morphology or doping level). ${ }^{11}$ A $5 \% \mathrm{Ni} / \mathrm{MnO}$ catalyst has been suggested to be particularly stable at low temperatures, exhibiting small MnO-interface stabilized $\mathrm{Ni}$ particles and a quite low propensity for surface carbon formation. ${ }^{49,50} \mathrm{Ni}$ particle sintering was offered as an explanation for deactivation at higher reaction temperatures. This catalyst material is therefore the ideal choice to decouple the effect of Ni particle sintering and the potential deactivation by the appearance of surface carbon, which is particularly aided by the appearance of crystalline graphite reflections that can be monitored during time-on-stream (Fig. 5). To illustrate the importance of in situ monitoring the carbon reactivity during the dry reforming reaction, we used the $5 \% \mathrm{Ni} / \mathrm{MnO}$ catalyst at different temperatures and reactant partial pressures. Changing the reactant ratio with time-on-stream results in a decrease in the deactivation rate of the catalyst, which can be correlated with the graphitic carbon growth and metal particle sintering as observed by in situ X-ray diffraction under DRM reaction conditions. We have shown that methane and carbon monoxide both separately yield graphitic surface carbon in the form of multiwalled carbon nanotubes, which can be oxidized by carbon dioxide. The correlation of catalytic experiments and in situ X-ray diffraction suggests that surface carbon acts as an intermediate in the carbon monoxide formation and that catalyst deactivation rather happens via metallic particle sintering. Fig. 5 shows a collection of in situ X-ray diffractograms and indicates the build-up of crystalline graphitic surface carbon at $600{ }^{\circ} \mathrm{C}$ during the measurement time of $150 \mathrm{~min}$ (highlighted region in the blue frame) in a $1: 1 \mathrm{CO}_{2}: \mathrm{CH}_{4}$ mixture. Increasing the reactant ratio to $\mathrm{CO}_{2}$ : $\mathrm{CH}_{4}=2: 1$ stopped the growth of carbon immediately and the amount of graphite remained constant for $75 \mathrm{~min}$ (not shown). Increasing the reaction temperature and observing the carbon reactivity at $800{ }^{\circ} \mathrm{C}$ (Fig. 5B) led to a swift decrease in the amount of carbon due to the thermodynamic feasibility of the coal gasification process in that particular temperature region. The schematic representation shown as inset in Fig. 5B summarizes the reactions at the $\mathrm{Ni}-\mathrm{MnO}$ interface.

\section{Summary and outlook}

The presented Highlight article summarized in five selected examples the importance of the occurrence and reactivity monitoring of crystalline species and compounds to derive structure-property relationships in heterogeneous catalysis. Despite being a bulk-related phenomenon, the tracking of crystalline structures during (self-)activation is indispensable to disentangle the mechanism of complex reactions such as methanol steam or methane dry reforming. There is a rich pool of ways in which crystalline species can contribute to 

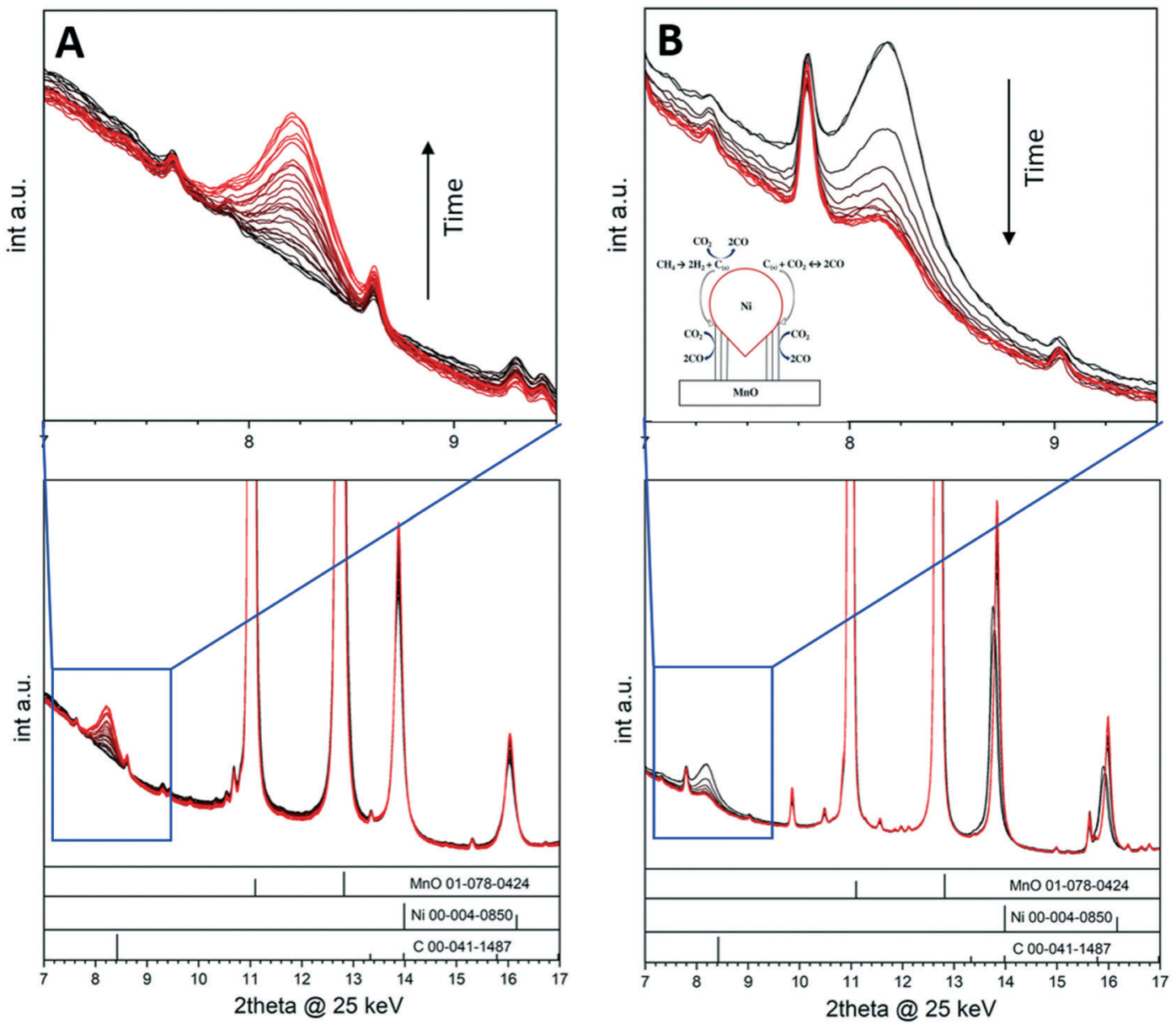

Fig. 5 In situ collected X-ray diffraction patterns on $5 \% \mathrm{Ni} / \mathrm{MnO}$. Panel A: Reaction temperature $600{ }^{\circ} \mathrm{C}$, reactant ratio: $\mathrm{CO}_{2}: \mathrm{CH}_{4}=1: 1$, reaction time: $150 \mathrm{~min}$. Panel B: Reaction temperature $800{ }^{\circ} \mathrm{C}$, reactant ratio: $\mathrm{CO}_{2}: \mathrm{CH}_{4}=2: 1$, reaction time: 75 min. A pattern has been collected every 5 min. The diffractogram regions marked by the blue squares are enlarged at the top of each panel and display the evolution of the (002) graphite reflection as a function of time. Reference patterns are indicated as bars at the bottom of each panel. Reproduced with permission from ref. 11, Copyright American Chemical Society, 2021.

the understanding of catalytic action of different catalyst materials, which underscores the widespread occurrence and validation of the concept. Simple binary oxides, complex oxides such as perovskites or Ruddlesden-Popper structures, intermetallic compounds and alloys, and (oxy-)carbides or metal-oxide composites during catalyst activation or reaction are all affected distinctly and differently. This includes, but is not limited to

- catalyst bulk reconstruction (e.g., the tetragonal-tomonoclinic $\mathrm{ZrO}_{2}$ polymorphic transformation),

- formation of transient structures (e.g., the observation of $\mathrm{La}_{2} \mathrm{NiO}_{4}$ en route from $\mathrm{LaNiO}_{3}$ to $\left.\mathrm{Ni} / \mathrm{La}_{2} \mathrm{O}_{3} / \mathrm{La}_{2} \mathrm{O}_{2} \mathrm{CO}_{3}\right)$,

- catalyst self-activation (e.g. decomposition of $\mathrm{Cu}_{51} \mathrm{Zr}_{14}$ during methanol steam reforming),

- epitaxial stabilization effects (e.g., the formation of $\mathrm{Cu} /$ tetragonal $\mathrm{ZrO}_{2}$ via decomposition of $\left.\mathrm{Cu}_{51} \mathrm{Zr}_{14}\right)$,

- stability issues (e.g., the reversible decomposition and re-formation of the oxycarbide electro-catalyst $\mathrm{ZrO}_{0.31} \mathrm{C}_{0.69}$ into $\mathrm{ZrC}$ and $\mathrm{ZrO}_{2}$ under oxidative and reductive atmospheres) and
- reactivity of crucial reaction intermediates (e.g., formation of La-oxycarbonate structures through carbon dioxide activation during the methane dry reforming of $\mathrm{LaNiO}_{3}$ or formation of reactive carbon).

Despite the importance of the bulk crystalline species for the understanding of heterogeneous catalysis, the concept is only as strong as the availability of in situ methods that allow the monitoring of the respective species and the input from overlapping research areas all contributing to the bigger picture. In the present case, inorganic chemistry and crystal engineering (via providing preparation pathways to the relevant crystalline samples), crystallography (providing the structural input) and materials science (catalyst characterization via sophisticated in situ characterization) work together to derive a clear picture of the catalytic properties and the establishment of structureproperty relationships. Insight into the development of crystalline structures is also given by complementary in situ imaging techniques, such as electron microscopy at high temperatures, which has seen tremendous advances recently especially in perovskite-related stability studies. ${ }^{51,52}$ 


\section{Conflicts of interest}

There are no conflicts to declare.

\section{Acknowledgements}

S. Penner acknowledges funding through projects F45 and I 2877-N34 of the Austrian Science Foundation (FWF) and the research platform "Advanced Materials" at the University of Innsbruck.

\section{References}

1 J. K. Norskov, T. Bligaard, B. Hvolbaek, F. Abild-Pedersen, I. Chorkendorff and C. H. Christensen, Chem. Soc. Rev., 2008, 37, 2163-2717.

2 R. Imbihl, R. J. Behm and R. Schlögl, Phys. Chem. Chem. Phys., 2007, 9, 3459-3459.

3 In-situ Characterization of Heterogeneous Catalysts, ed. J. A. Rodriguez, J. C. Hanson and P. J. Chupas, Wiley, 2013.

4 S. Sharna, M. Bahri, C. Bouillet, V. Rouchon, A. Lambert, A. Gay, D. Chiche and O. Ersen, Nanoscale, 2021, 13, 9747-9756.

5 E.-M. Köck, et al., Dalton Trans., 2017, 46, 4554-4570.

6 O. Kwon, S. Sengodan, K. Kim, G. Kim, H. Jeong, J. Shin, Y. Ju, J. Han and G. Kim, Nat. Commun., 2017, 8, 1-7.

7 K. T. Möller, B. Hansen, A. Dippel, J.-E. Jörgensen and T. R. Jensen, Z. Anorg. Allg. Chem., 2014, 640, 3029-3043.

8 L. Mayr, D. Schmidmair, M. Armbrüster, J. Bernardi, S. Schwarz, B. Klötzer and S. Penner, ChemCatChem, 2016, 8, 1778-1781.

9 N. Bonmassar, et al., ACS Catal., 2020, 10, 1102-1112.

10 M. Bekheet, et al., ACS Catal., 2021, 11, 43-59.

11 A. Gili, et al., ACS Catal., 2018, 8, 8739-8750.

12 N. Shakibi Nia, D. Hauser, L. Schlicker, A. Gili, A. Doran, A. Gurlo, S. Penner and J. Kunze-Liebhäuser, ChemPhysChem, 2019, 21, 1-8.

13 S. Bhattar, M. Abedin, S. Kanitkar and J. Spivey, Catal. Today, 2021, 365, 2-23.

14 C. Batiot-Dupeyrat, G. Valderrama, A. Meneses, F. Martinez, J. Barrault and J. Tatibouët, Appl. Catal., A, 2003, 248, 143-151.

15 G. Sierra Gallego, F. Mondragón, J. Tatibouët, J. Barrault and C. Batiot-Dupeyrat, Catal. Today, 2008, 133-135, 200-209.

16 A. Doran, L. Schlicker, C. M. Beavers, S. Bhat, M. F. Bekheet and A. Gurlo, Rev. Sci. Instrum., 2017, 88, 13903-1-13903-6.

17 L. Schlicker, A. Doran, P. Schneppmüller, A. Gili, M. Czasny, S. Penner and A. Gurlo, Rev. Sci. Instrum., 2018, 89, 339041-33904-4.

18 M. Armbrüster, Sci. Technol. Adv. Mater., 2020, 21, 303-322.

19 M. Armbrüster, R. Schlögl and Y. Grin, Sci. Technol. Adv. Mater., 2014, 15, 034803.

20 A. Dasgupta and R. M. Rioux, Catal. Today, 2019, 330, 2-15.

21 S. Furukawa and T. Komatsu, ACS Catal., 2017, 7, 735-765.

22 S. Penner and P. D. K. Nezhad, ACS Catal., 2021, 11, 5271-5286.
23 M. Behrens and M. Armbrüster, Methanol Steam Reforming, in Catalysis for Alternative Energy Generation, ed. L. Guczi and A. Erdôhelyi, Springer, New York, New York, NY, 2012, pp. 175-235.

24 K. Ploner, et al., J. Catal., 2020, 391, 497-512.

25 L. Mayr, N. Köpfle, B. Klötzer, T. Götsch, J. Bernardi, S. Schwarz, T. Keilhauer, M. Armbrüster and S. Penner, J. Phys. Chem. C, 2016, 120, 25395-25404.

26 N. Köpfle, L. Mayr, D. Schmidmair, J. Bernardi, A. KnopGericke, M. Hävecker, B. Klötzer and S. Penner, Catalysts, 2017, 7, 53-770.

27 H. Purnama, F. Girgsdies, T. Ressler, J. H. Schattka, R. A. Caruso, R. Schomäcker and R. Schlögl, Catal. Lett., 2004, 94, 61-68.

28 S. T. Oyama, The Chemistry of Transition Metal Carbides and Nitrides, Springer Netherlands, Dordrecht, 1996.

29 H. H. Hwu and J. G. Chen, Chem. Rev., 2005, 105, 185-212.

30 B. M. Tackett, W. Sheng and J. G. Chen, Joule, 2017, 1, 253-263.

31 S. T. Oyama, Catal. Today, 1992, 15, 179-200.

32 R. B. Levy and M. Boudart, Science, 1973, 181, 547-549.

33 S. G. Jingguang Chen, W. Wan, B. M. Tackett and J. G. Chen, Chem. Soc. Rev., 2017, 46, 1807-1817.

34 A. L. Stottlemyer, T. G. Kelly, Q. Meng and J. G. Chen, Surf. Sci. Rep., 2012, 67, 201-232.

35 Y. C. Kimmel, X. Xu, W. Yu, X. Yang and J. G. Chen, ACS Catal., 2014, 4, 1558-1562.

36 M. C. Weidman, D. V. Esposito, Y. C. Hsu and J. G. Chen, J. Power Sources, 2012, 202, 11-17.

37 L. Calvillo, D. Fittipaldi, C. Rüdiger, S. Agnoli, M. Favaro, C. Valero-Vidal, C. Di Valentin, A. Vittadini, N. Bozzolo and S. Jacomet, J. Phys. Chem. C, 2014, 118, 22601-22610.

38 L. Calvillo, G. García, A. Paduano, O. Guillen-Villafuerte, C. Valero-Vidal, A. Vittadini, M. Bellini, A. Lavacchi, S. Agnoli and A. Martucci, ACS Appl. Mater. Interfaces, 2016, 8, 716-725.

39 C. Rüdiger, M. Favaro, C. Valero-Vidal, L. Calvillo, N. Bozzolo, S. Jacomet, J. Hein, L. Gregoratti, S. Agnoli and G. Granozzi, ACS Omega, 2017, 2, 631-640.

40 C. Griesser, et al., ACS Catal., 2021, 11, 4920-4928.

41 D. Hauser, A. Auer, J. Kunze-Liebhäuser, S. Schwarz, J. Bernardi and S. Penner, RSC Adv., 2019, 9, 3151-3156.

42 M. Kogler, E. M. Köck, S. Vanicek, D. Schmidmair, T. Götsch, M. Stöger-Pollach, C. Hejny, B. Klötzer and S. Penner, Inorg. Chem., 2014, 53, 13247-13257.

43 G. K. Bansal and A. H. Heuer, Acta Metall., 1972, 20, 1281-1289.

44 A. Wolfbeisser, O. Sophiphun, J. Bernardi, J. Wittayakun, K. Föttinger and G. Rupprechter, Catal. Today, 2016, 277, 234-241.

45 A. T. Ashcroft, A. K. Cheetham, M. L. H. Green and P. D. F. Vernon, Nature, 1991, 352, 225-232. 
46 J. R. Rostrup-Nielsen, J. Catal., 1993, 144, 38-45.

47 M. C. J. Bradford and M. A. Vannice, Appl. Catal., A, 1996, 142, 73-80.

48 N. Köpfle, et al., Angew. Chem., Int. Ed., 2018, 57, $1-7$.

49 X. Xie, T. Otremba, P. Littlewood, R. Schomäcker and A. Thomas, ACS Catal., 2013, 3, 224-229.
50 P. Littlewood, X. Xie, M. Bernicke, A. Thomas and R. Schomäcker, $\mathrm{Ni}_{0.05} \mathrm{Mn}_{0.95} \mathrm{O}$ catalysts for the dry reforming of methane, Catal. Today, 2015, 242, 111-118.

51 S. Singh, E. Prestat, L.-F. Huang, J. M. Rondinelli, S. J. Haigh and B. A. Rosen, Sci. Rep., 2017, 7, 1-7.

52 S. Singh, D. Zubenko and B. A. Rosen, ACS Catal., 2016, 6, 4199-4205. 